\title{
Empathy and attitude towards communication skill learning as a predictor of patient-centered attitude: $A$ cross-sectional study of dental students in Korea
}

\author{
Minjung Lee \\ Seoul National University \\ Jungjoon Ihm ( $\sim$ ijj127@snu.ac.kr) \\ Seoul National University https://orcid.org/0000-0002-3136-5956
}

\section{Research article}

Keywords: patient-centered care, patient-centered attitudes, empathy, communication skills attitudes, dental students

Posted Date: August 3rd, 2020

DOI: https://doi.org/10.21203/rs.3.rs-47583/v1

License: (c) (i) This work is licensed under a Creative Commons Attribution 4.0 International License. Read Full License

Version of Record: A version of this preprint was published at BMC Medical Education on April 21st, 2021. See the published version at https://doi.org/10.1186/s12909-021-02674-z. 


\section{Abstract}

Background: Enhancing medical students' practicing patient-centered care is a goal of medical schools. In addition to exploring the demographic and academic factors of the students, it is necessary to identify other attitudes and perceptions that may influence the student's patient-centered attitude and inclination toward communication skill learning. This study aimed to assess patient-centered attitudes among dental students in Korea and identify the association between the students' characteristics and empathy, communication skill attitude, and patient-centered attitude.

Methods: Data were collected via a cross-sectional online survey, and 312 dental students were included in the analyses. The study participants completed the Patient-provider Orientation Scale (PPOS), the Interpersonal Reactivity Index (IRI), and the Communication Skills Attitudes Scale (CSAS). Analyses were performed using independent samples t-tests, hierarchical multi-variable regression, and ANOVA with a post-hoc Tukey test.

Results: The students tend to be moderately doctor-centered toward the caring aspect and slightly more doctororiented toward the sharing aspect of patient-centered attitudes. Being male and a longer academic period in dentistry were related to a doctor-centered attitude. Empathy and attitude toward on learning communication skills were related to a patient-centered attitude and "empathic concern" had the greatest significant impact on patient-centered attitude.

Conclusion: The current study supports the idea that education programs should focus on enhancing empathy, emphasizing positive attitudes on learning communication skills, and conducting follow-up education sessions to prevent students from becoming less patient-centered with an increase in duration of their academic period.

\section{Background}

The change in the disease pattern from infectious disease to chronic disease, increase in the accessibility of health information via the Internet, and the rise of medical consumerism has made patients more actively involved in medical decision-making [1-3]. Given that the conventional imbalance of power between patients and physicians was due to the gap in the amount of health information, the above-mentioned factors have done a great deal to change the relationship between patients and physicians. The change in the doctor-patient relationship is further emphasized by "patient-centered care" that aims to identify and respond to thoughts and emotions related to the patient's health problems and to establish a common ground for the patient's health problems, treatment, and the roles that the patients and doctors recognize [4]. In recent decades, increasing evidence has suggested that patient-centered care leads to positive outcomes, including higher patient satisfaction, increased adherence to medication and behavioral regimens, higher provider satisfaction, and superior clinical outcomes [5-8]. Moreover, patient-centered care is a medical principle that has been discussed most frequently in the previous few decades [9].

Currently, in Korea, there is an active movement to create a patient-centered health care system and provide patientcentered care. The Ministry of Health and Welfare in Korea is proposing a policy goal to provide patient-centered medical services, and it is rapidly spreading via the performance of Patient Experience evaluation since 2017 [10] and public health policy initiatives such as "in-depth consultations of over 15 minutes" health services for serious and noncurable diseases patients since 2018 [11]. However, as per a recent OECD Health Statistics report, the number of outpatient visits is among the highest among OECD countries (16 times a year), $87.1 \%$ of the patients easily understood the doctor's explanation (13th among 19 countries) and $81.8 \%$ had the opportunity to speak up with questions or concerns to the provider (13th among 18 countries), the lowest among OECD countries [12]. However, one of the obvious reasons why patient-centered care is not regularly practiced is that providers are not trained to deliver this type of healthcare. 
Enhancing medical students' practicing patient-centered care is a goal of medical schools $[13,14]$. In order to promote the benefits of both patients and healthcare providers, educational programs for healthcare professionals in many countries are increasingly being adopting in the curriculum that advocates patient-centered approach. The curriculum also aims to respond to a decrease in the patient-centered attitudes in the medical curriculum. Despite educational efforts, the decline in patient-centered attitudes during the course of medical education has been observed in longitudinal studies in the USA and Greece and been inferred from several cross-sectional studies internationally [15, 16]. The patient-centered attitude of medical students remained at a certain level during the preclinical stage [17, 18]; however, this has decreased during the clinical years $[19,20]$. Reductions in patient-centered attitudes in medical school may result from the heavy emphasis that medical programs place on the biological aspects of disease as well as the emotional burn-out medical students may develop as their responsibilities and work load intensify [21]. Moreover, sex-based differences have been consistently reported in previous studies, with female students generally exhibiting a more patient-centered attitude than male students [15, 22-24]. A previous meta-analysis of observational studies of physician communication indicated that female physicians engaged in more communication that could be considered patient-centered than their male counterparts [25]; therefore, sex-based differences in attitudes toward physician-patient relationships might have started at the stage of medical education. In this regard, infusing patientcenteredness into medical school curricula could help future providers deliver quality care and build effective health systems; however, it requires an understanding of the existing levels and patterns of attitudes toward patientcenteredness [26].

In addition to exploring the demographic and academic factors of the students, it is necessary to identify other attitudes and perceptions that may affect the student's patient-centered attitude. Empathy, an essential characteristic that is commonly included in many different definitions of the concept of patient-centered care $[27,28]$ can be a potential factor that affects patient-centered attitude. Empathy can be defined as "the ability to understand the patients' situation, perspective, and feelings, and to communicate that understanding to the patient" [29]; it is an essential component of both, competence as a doctor and the physician-patient relationship [30, 31]. In particular, empathy has been suggested to strengthen the therapeutic alliance between the provider and patient and could be a pathway through which patient-centeredness impacts patients and ultimately patient outcomes [8]. Few studies have found a positive association between empathy and patient-centered attitude among medical students [32] and dental and medical students [33]. More importantly, it is found that experiences can modify empathy and can be learned via a proper education program during medical school. Increasing evidence has shown positive results for several educational programs designed to improve empathy among medical students, residents, and doctors [34, 35]. Therefore, empathy might be a potential key to fostering patient-centered attitude through education.

In addition, another factor expected to contribute to patient-centered attitude is attitude toward communication skill learning. Communication skills with patients and other healthcare practitioners are essential for patient-centered clinical practice and represent an important medical competence of doctors. Rees, Sheard, and Davies published the Communication Skills Attitudes Scale (CSAS) that measures students' attitudes toward learning communication skills during medical school [36]. Previous studies have reported that female students have more positive attitudes than male subjects and that students in their early stages have more positive attitudes than those who are in their later years of education in medical school $[37,38]$. Student's positive or negative evaluations of learning communication skills may influence patient-centered attitudes. To our knowledge, no study has examined the effect of communication learning attitudes on patient-centered attitudes.

The concept of patient-centered care is becoming increasingly prominent in the field of dentistry. While not as widely applied or researched as in general dental medicine, references to patient-centered care and its principles are becoming more prevalent both in the dental literature and in policy documents. However, despite the growing 
importance of this concept, there is lack of research on the attitude toward patient-centeredness among dental students and on how it can be inculcated and practiced in clinical settings [39]. This study aimed to examine the existing levels and patterns of patient-centered attitude via an analysis of the related sociodemographic and academic factors and identification of the association between empathy and patient-centered attitude. This study ultimately aimed to serve as a foundation to develop patient-centered curriculum in dental education.

\section{Methods}

\section{Participants}

This study was approved by the Institutional Review Board of the School of Dentistry, the Seoul National University, Seoul, Republic of Korea, as per the policy on research with human participants (IRB No. S-D20200028). The participants of this cross-sectional study were 312 dental students enrolled at the Seoul National University School of Dentistry, Seoul, Republic of Korea in the spring 2020 semester. These participants completed the Patient-provider Orientation Scale (PPOS), the Interpersonal Reactivity Index (IRI), and the CSAS. All the respondents had provided informed consent for their data to be included in this study.

\section{Data collection}

A cross-sectional survey was designed to evaluate the dental students' patient-centered orientation, empathy, and communication skills learning attitudes using an anonymous online questionnaire. The survey was conducted via an online platform with Google survey. The Korean Government has asked the general public to minimize face-to-face interaction and isolate themselves at home; therefore, potential respondents were electronically invited. They completed the questionnaires in Korean via an online survey platform. All the respondents provided informed consent. The process of data collection occurred over a period of 6 weeks (June 2 to June 15, 2020).

\section{Measurements}

\section{Patient-Practitioner Orientation Scale (PPOS)}

The study participants completed the PPOS, an 18-item self-report measure that uses two subscales, Caring (importance of understanding patients' perspectives) and Sharing (importance of sharing control with the patient) to quantify the roles that providers and patients believe that each should play in the process of their interaction along a doctor-centered/patient-centered continuum $[16,40]$. The PPOS was translated into the Korean language and modified as per the Korean healthcare context by two independent researchers. Then, another researcher who had not seen the original version translated the Korean version back to English, and adjustments in the Korean version were made until the re-translation yielded a version similar to the original PPOS. A sample items are "Patients should be treated as if they are partners of the doctor, equal in power and status" (Sharing subscale), "When doctors ask a lot of questions about a patient's background, they are prying too much into personal matters" (Caring subscale). The responses were rated on a 6-point Likert-type scale ranging from 1 to 6 with 1 indicating "not at all" and 6 indicating "extremely."

\section{Interpersonal Reactivity Index (IRI)}

In this study, the Korean version of the IRI (K-IRI) that was translated and validated by Kang et al. [41] was used. This K-IRI has been used to assess empathy for Korean medical students and is found to have adequate psychometric properties [42]. The IRI was designed to measure individual differences in empathy among the general public. It includes 28 items with response options on a five-point Likert-type scale $(0=$ does not describe me very well, $4=$ describes me very well). The IRI measures different aspects of empathy, including 1) Perspective Taking that 
measures the tendency to spontaneously adopt the psychological viewpoint of others; 2) Fantasy that measures the ability to transform oneself into characters of movies, books, plays, etc.; 3) Empathic Concern that measures the ability to assess "other" oriented feelings of sympathy and concern for unfortunate others; and 4) Personal Distress that measures "self" oriented feelings of distress and unease in interpersonal settings, using a 28-item Likert scale based questionnaire.

\section{Communication Skills Attitudes Scale (CSAS)}

The CSAS was designed to measure the attitudes toward communication skill learning [36], is most specific to teaching and learning of communication skills, and is the most widely used and validated scale [43]. The CSAS uses a two-factor scale that includes positive and negative attitudes toward learning communication skills and comprises 26 items, each with 13 items. The contents of the Positive Attitudes Scale (CSAS-PAS) are positively worded (e.g., "In order to be a good doctor I must have good communication skills"), and the contents of the Negative Attitudes Scale (CSAS-NAS) are negatively worded (e.g., I don't need good communication skills to be a doctor). The measurement uses a 5-point Likert scale ( 1 = Strongly disagree and $5=$ Strongly agree). The scores for every scale ranged from 1365 , with higher scores revealing stronger positive or negative attitudes toward learning communication scale.

\section{Data analyses}

All statistical analyses were performed using R version 3.5.1 (R Foundation for Statistical Computing, Vienna, Austria). All the results of quantitative variables were reported either as mean (M), standard deviation (SD), or frequency (percentage\%). Independent t-test was used to compare the differences in the PPOS scores, IRI scores, and CSAS scores of male and female dental students. Multivariate hierarchical linear regression analysis was used to examine the effect of sociodemographic, academic factors, and empathy and communication skills attitudes on patientcentered orientation. ANOVA with a post-hoc Tukey test was employed to examine the average differences the among student's future career plans for patient-centered attitude.

\section{Results}

\section{Participants' demographic and education-related characteristics}

We collected surveys from 312 students that included 177 men (56.7\%) and 135 women (43.3\%), with a mean age of 22 years $(M=22.39, S D=3.02)$ (Table 1$)$. The study school has been operating as a dental college and a professional graduate-entry school system simultaneously where students from both tracks merge and work together at the level of 4-year Doctor of Dental Surgery (DDS) degree. Among the study participants, $61.9 \%$ belongs to the dental college, and $38.1 \%$ belonged to professional graduate-entry school. The average academic duration was 2.92 y $(S D=1.77)$. The students' demographic and academic characteristics are presented in Table 1.

\section{Patient-centered attitude, empathy, and communication skills learning attitude}

The mean PPOS score for the entire sample was 4.09 (SD = 0.45), near the midpoint of the possible range $(1-6)$. The mean score was slightly lower for the sharing subscale $3.78(S D=0.54)$ and slightly higher for the caring subscale $4.41(S D=0.52)$ (Table 2). Cronbach's alpha was high for the full scale $(a=0.72)$ and had an acceptable level for the caring subscale $(\alpha=0.59)$ and the sharing subscale $(a=0.61)$. Higher PPOS values indicate more patient-centered attitude in terms of sharing power with patients and holistic patient care. Descriptive analysis was performed on the four subscales of empathy, and the results are presented in Table 2. Among the four subscales, perspective taking score was the highest $(M=3.69, S D=0.50)$, followed by empathic concern $(M=3.66, S D=0.52)$, fantasy $(M=3.52$, 
$S D=0.62)$, and personal distress $(M=2.95, S D=0.51)$. Cronbach's alpha was high for the full scale $(a=0.77)$, the perspective taking subscale $(a=0.64)$, empathic concern $(a=0.68)$, fantasy $(a=0.75)$, and the personal distress ( $a=$ $0.66)$. The mean value of the CSAS showed that the students have positive attitudes toward learning communication skills (Table 2). The CSAS-PAS score $(M=54.15, S D=6.36)$ was higher than the CSAS-NAS score $(M=32.65, S D=$ 5.96) (Table 2). Among the CSAS-PAS items, "Learning communication skills has helped or will help me respect patients." ( $M=4.51, S D=0.61)$ had the highest score, and among the CSAS-NAS items, "I haven't got time to learn communication skills" $(M=3.29,1.02)$ had the highest score. Cronbach's alpha was high for CSAS-PAS scale $(a=$ $0.88)$ and CSAS-NAS scale $(a=0.71)$.

\section{Sex-based differences in patient-centered attitudes, empathy, and communication skills attitude}

By examining the patterns of PPOS score, IRI, and CSAS, we assessed whether sex-based differences exist. We found significant differences between female and male students. Female students had a significantly higher overall PPOS score and sharing subscale than male students. The score of the female students PPOS caring subscale was higher than that of the male students; however, the difference was not statistically significant. With respect to IRI, fantasy, empathic concern, and personal distress had higher scores in female students and perspective taking was higher in men. However, only the differences for personal distress were significant between men and women $(P<0.001)$. Moreover, there was no significant sex-based difference in the CSAS-PAS and CSAS-NAS (Table 3).

\section{The effect of empathy and communication skills attitude on patient-centered attitudes}

Influencing factors on patient-centered attitudes from among demographic factors, academic factors, empathy and communication skills learning attitude were assessed (Table 4). The investigated factors accounted for about $31.3 \%$ of the variance in the total PPOS score, $F(9,302)=16.72$, adjusted $R^{2}=0.31, p<0.001$. Sex (female) $(\beta=0.10, p=$ $0.04)$, academic period ( $\beta=-0.03, p=0.03)$, and empathic concern $(\beta=0.19, p<0.001)$ were significant individual predictors of the overall PPOS score. Both, positive and negative attitudes about communication skills were related to the overall PPOS score. Admission type and other subscales of empathy except empathic concern did not influence the total PPOS score. Similar to the overall PPOS score, sex (female) $(\beta=0.15, p=0.01)$, academic period $(\beta=-0.06, p$ $<0.001)$, and empathic concern $(\beta=0.16, p=0.02)$ were significant variables that influenced the PPOS sharing subscale. However, unlike the overall PPOS score, only negative attitude of learning communication skills $(\beta=-0.31, p$ $<0.001$ ) was associated with the sharing subscale of the PPOS score. Among the influencing factors, the effect of empathic concern was the strongest. The investigated factors accounted for approximately $17.9 \%$ of the variance in the sharing subscale of the PPOS score. Finally, for the PPOS caring subscale, none of the demographic factors were significant. Empathy (fantasy) $(\beta=0.13, p=0.01)$, empathic concern $(\beta=0.22, p<0.001)$, and personal distress ( $\beta=$ $-0.12, p=0.04$ ) were significant individual predictors of the PPOS caring subscale. Moreover, both, positive and negative attitudes on the communication scale were related to the PPOS caring subscale. The investigated factors accounted for about $31.0 \%$ of the variance in the caring subscale of the PPOS score.

\section{Differences in patient-centered attitudes according to students' future career plans}

We also investigated the patterns of patient-centered attitudes as per the future career plans of the students. About $50 \%$ of the students wanted to work in private practice $(50.6 \%)$, followed by those who wanted to work in academics (27.9\%), those who wished to get employed at a dental clinic (12.5\%), and those who were unsure of their future plans (9.0\%). When we compared the PPOS score among those with different future career plans, students who planned to work at dental clinics showed the highest scores overall PPOS, for both subscales. However, only the overall PPOS score and sharing score were significantly lower among students who planned to work in private practice as compared to those who planned to work in academics or wished to join dental clinic (Table 5). 


\section{Discussion}

This study aimed to assess patient-centered attitudes among dental students in Korea and identify the association between the students' characteristics and empathy, communication skill attitude and patient-centered attitude. Our results have shown that students tend to be more doctor-centered in "sharing" (i.e., sharing responsibilities and power in decision-making with patients) than in "caring" (i.e., understanding patient's perspectives). Being male and having a longer academic period in the field of dentistry were related to a doctor-centered attitude. Empathy and attitudes on learning communication skills were related to a patient-centered attitude. Among the influencing factors, empathic concern had the highest and significant impact on patient-centered attitude. The current study supports that education programs should focus on enhancing empathy, emphasizing positive attitudes on learning communication skills, and on conducting follow-up education sessions to prevent students from becoming less patient-centered with an increase in their academic period.

Our results indicate that our sample of Korean dental students was moderately oriented toward the caring aspect of patient-centeredness and slightly less oriented toward the sharing aspect. Compared to that in previous studies, the overall PPOS score (4.09) was higher (more patient centered) than the mean reported among Indian dental students (3.38) [24] and Korean (3.90) [44] and Greek (3.81) [45] medical students; however, it was lower than that in dental students (4.37) [46] and medical students in the USA (4.57) [16] and medical students in Japan (4.56) [47] and Brazil (4.66) [48]. However, unfortunately, we could not compare with multiple studies conducted on dental students owing to the availability of limited trials. Moreover, scores from our study and those that have been cited from previous studies should be interpreted with caution because the internal consistency was either inadequate or not reported in the publications. Nevertheless, these results indicate that education is needed to improve patient-centered attitudes among dental students.

Previous studies [15, 22-24] have consistently reported that female students generally had a more patient-centered attitude than male students. The influence of sex was more evident for the sharing component than the caring component. A previous meta-analysis of observational studies on physician communication indicated that female physicians engaged in more communication that could be considered patient-centered, such as addressing the patient's psychosocial issues, using emotion talk and positive talk, and more actively incorporating patient input [25]. This result suggests that patient-centered attitudes of medical students were maintained after graduation and influence the patient-centeredness of the practicing style in clinical settings. Therefore, it is important to emphasize patient-centered attitudes during pre-medical education. Further studies targeting gender differences with specific interventions are needed, such as formal curriculum, professional development programs, and patient simulations.

The study duration has been identified as a significant factor that lowers the patient-centered attitudes. Previous studies have showed that the attitudes of students in the later years of medical school are more doctor-centered or paternalistic than those in students in earlier years $[15,16,47]$. Although the design of this study is a cross-sectional study, these results provide evidence that patient-centered erosion occurs among students of dentistry. These results suggest that it will be very challenging to develop an effective curriculum that improves the patient-centered attitude of Korean dental students and maintains them after graduation.

In this study, empathy was a key contributor of the patient-centered attitude of dentistry students, in line with earlier studies $[46,49]$. Compared to previous studies that have used the Jefferson Scale of Physician Empathy (JSPE), this study measured students' empathy using the IRI. The JSPE is a measure of empathy that was designed to measure empathy in medical and health professionals [50], while IRI describes a general empathic attitude that is not specifically related to encounters with patients [51]. Although both the measures are broadly applied to evaluate the 
empathy disposition of medical or dental student studies, IRIs have strengths in that they examine the relationship between four individual aspects of empathy and social function, self-esteem, emotions, and sensitivity measures for others [51-53]. Therefore, we could examine the effect of each of the four individual aspects on patient-centered attitude.

Empathy was the most important predictor of patient-centered attitudes in terms of both sharing and caring because it explained $4.8 \%$ and the $18.1 \%$ of the sharing and caring variance, respectively. In other words, our results showed that dental students who experienced pity or were touched by others and were soft-hearted were associated with both the components of sharing information and decision-making with the patient, and caring about patient's expectations, preferences, and emotions. In particular, among the aspects of empathy, empathic concern was the most important predictor of patient-centered attitudes and the only aspect that significantly affected the "sharing" subscale of patientcentered attitude. According to Hojat and his colleagues, empathic concern is a cognitive component of empathy that assesses "other-oriented" feeling of sympathy and concern for unfortunate others [54] and is more relevant to patient care situations than other aspects $[50,53]$. The ability to assess the patients' feelings and concerns can help medical students agree with the idea of sharing aspects of patient-centered attitude, that patients should be treated as partners with the doctor with equal power and status, and that doctors should share information and try to share responsibility in decision-making. Empathic concern is not only measurable, but also teachable [55]; therefore, it can be provided as an important educational content to improve patient-centered attitude of medical and dental students.

When it comes to the caring aspect of patient-centered attitude, not only "empathic concern," but also "fantasy" and "personal distress" aspects of empathy were positively associated with it significantly. "Fantasy" refers to the extent to which the respondents transpose themselves imaginatively into the feelings and actions of others [54], which are likely to appraise affective component of empathy. This result suggests that the ability to imagine and engage a patient's feelings is related to being open and warm and fostering therapeutic relationships with the patients. Interestingly, "personal distress" has shown a negative impact on caring for a patient-centered attitude. The personal distress aspect of empathy refers to the extent of an individual's feelings of anxiety and discomfort owing to a negative experience [51]. The emotional aspect of this empathy may relate to the student's preference for more instrumental interactions rather than psychosocial interactions with patients as well as physician-centered roles in patient-physician relationships. This is consistent with previous studies showing that medical students with high scores in personal distress prefer limited exposure to affectively charged situations and less contact or interaction with patients [51, 56,57]. Moreover, too much personal distress type of empathy can sometimes produce higher levels of burn-out, terms "compassion fatigue" [58, 59].

Our study suggests that the type of empathy that students manifest contributes to the PPOS score in terms of the role they prefer in patient-physician relationships in both sharing and caring. In this study, empathic concern and fantasy type of empathy tended to be associated with more patient-centered attitudes, while personal distress type of empathy was associated with more doctor-centered attitude. This may have implications on the developmental support provided for the medical and dental students. For example, the present findings suggest that students with low empathic concern and fantasy and high personal distress type of empathy may be at a higher risk of employing physician-centered practicing style and may need more intensive training support. Several studies have shown the effectiveness of various educational interventions in developing medical student empathy $[42,60]$. Therefore, curricula targeted to increase empathic concern and fantasy type of empathy and decrease personal distress type of empathy can be effective in enhancing the patient-centered attitudes of medical and dental students.

Moreover, attitudes on learning communication skills were a significant factor that affected the students' patientcentered attitude; negative attitudes were related to doctor-centered attitude and positive attitudes were related to 
patient-centered attitude. Therefore, teaching and emphasizing the importance of communicating with patients can help students develop a more patient-centered attitude toward caring and sharing. For example, efforts to make students believe that learning communication skills can help enhance their practice and provide enough time to learn communication skills can be a practical and efficient way to enhance the patient-centeredness of the student's attitude on provider-patient relationships.

This study has certain limitations. The first limitation is related to the use of the IRI as a measure of empathy. Although the IRI is a widely used measure of empathy in research in the field of education of health professions and can assess both, the cognitive and emotional attributes of empathy, it describes a general empathic attitude that is not specifically related to encounters with patients. Second, the participants of our study were from only one Korean dental school; therefore, the generalization ability of the present results is limited. A possible suggestion for future studies is the use of a multi-centric research design.

\section{Conclusions}

The current study supports the idea that education programs should focus on enhancing empathy, emphasizing positive attitudes on learning communication skills, and conducting follow-up education sessions to prevent students from becoming less patient-centered with an increase in duration of their academic period. Patient-centered attitude can and must be taught. Our findings provide useful insights for developing an effective program on enhancing dental students' practicing patient-centered care by investigating the students' patient-centered attitude and the association with student's demographic and academic characteristics as well as aspects of empathy.

\section{Declarations}

\section{Ethics Approval and Consent to Participate}

The study was approved by the Institutional Review Board (IRB) of Seoul National University School of Dentistry (IRB No. S-D20200028). All participants were aware that they were taking part in this research and gave written informed consent via an online platform with Google survey in addition to confirming that they would allow us to use their collected data anonymously for publication. All the data were anonymously collected and analyzed.

\section{Consent for Publication}

Not Applicable

\section{Competing Interests}

The authors declare that they have no competing interests.

\section{Authors' contributions}

All authors have read and approved the manuscript. Conceptualization: Lee MJ; Methodology: Lee MJ; Formal analysis: Lee MJ, Ihm JJ; Data curation: Ihm JJ; Investigation: Lee MJ; Writing - original draft preparation: Lee MJ, Ihm JJ; Writing - review and editing: Lee MJ, Ihm JJ

\section{Funding}

Not Applicable 


\section{Questionnaires}

\section{Patient-Practitioner Orientation Scale (PPOS)}

Haidet P, Dains JE, Paterniti DA, Hechtel L, Chang T, Tseng E, Rogers JC: Medical student attitudes toward the doctorpatient relationship. Medical Education 2002, 36(6):568-574.

Krupat E, Yeager CM, Putnam S: Patient role orientations, doctor-patient fit, and visit satisfaction. Psychology \& Health 2000, 15(5):707-719.

\section{Interpersonal Reactivity Index (IRI)}

Kang I, Kee S-W, Kim S-E, Jeong B-S, Hwang J-H, Song J-E, Kim J-W: Reliability and validity of the Korean-version of Interpersonal Reactivity Index. Journal of Korean Neuropsychiatric Association 2009, 48(5):352-358.

\section{Communication Skills Attitudes Scale (CSAS)}

Anvik T, Gude T, Grimstad H, Baerheim A, Fasmer OB, Hjortdahl P, Holen A, Risberg T, Vaglum P: Assessing medical students' attitudes towards learning communication skills-which components of attitudes do we measure? BMC Medical Education 2007, 7(1):4.

\section{Availability of data and materials}

The datasets used and/or analyzed during the current study are available from the corresponding author on reasonable request.

\section{ORCID}

Minjung Lee https://orcid.org/0000-0002-0479-6523

Jungjoon Ihm http://orcid.org/0000-0002-3136-5956

\section{Abbreviations}

Patient-Practitioner Orientation Scale (PPOS), Interpersonal Reactivity Index (IRI), Communication Skills Attitudes Scale (CSAS), Positive Attitudes Scale (CSAS-PAS), Negative Attitudes Scale (CSAS-NAS)

\section{References}

1. Hardey M: Doctor in the house: the Internet as a source of lay health knowledge and the challenge to expertise. Sociology of Health \& IIIness 1999, 21(6):820-835.

2. Lee C-j, Gray SW, Lewis N: Internet use leads cancer patients to be active health care consumers. Patient Education and Counseling 2010, 81:S63-S69.

3. Lupton D: Consumerism, reflexivity and the medical encounter. Social science \& medicine 1997, 45(3):373-381.

4. Epstein RM, Street RL: The values and value of patient-centered care. Annals of Family Medicine 2011.

5. Buller MK, Buller DB: Physicians' communication style and patient satisfaction. Journal of health and social behavior 1987:375-388. 
6. Kaplan SH, Greenfield S, Ware Jr JE: Assessing the effects of physician-patient interactions on the outcomes of chronic disease. Medical care 1989:S110-S127.

7. Roter DL, Hall JA, Katz NR: Relations between Physicians' Behaviors and Analogue Patients' Satisfaction, Recall, and Impressions. Medical Care 1987, 25(5):437-451.

8. Street Jr RL, Makoul G, Arora NK, Epstein RM: How does communication heal? Pathways linking clinician-patient communication to health outcomes. Patient education and counseling 2009, 74(3):295-301.

9. Ishikawa H, Hashimoto H, Kiuchi T: The evolving concept of "patient-centeredness" in patient-physician communication research. Social Science and Medicine 2013, 96:147-153.

10. Han SK, Kim TH: What Hospital Characteristics Influence the Patient Experiences. Public Health Affairs 2019, 3(1):121-132.

11. Sohn K-H, Nam S, Joo J, Kwon YJ, Yim J-J: Patient-centeredness during in-depth consultation in the outpatient clinic of a tertiary hospital in Korea: paradigm shift from disease to patient. Journal of Korean medical science 2019, 34(15).

12. Sun K-HKJ-Y: Quality of Korea's health care and policy according to OECD statistics. In. Edited by Service HIRA, vol. 12. Korea: Health Insurance Review \& Assessment Service; 2018: 45-59.

13. Roter DL, Hall JA: Physician gender and patient-centered communication: a critical review of empirical research. Annual Review of Public Health 2004, 25:497-519.

14. Kaufman DM, Laidlaw TA, Langille D, Sargeant J, MacLeod H: Differences in medical students' attitudes and selfefficacy regarding patient-doctor communication. Academic Medicine 2001, 76(2):188.

15. Tsimtsiou Z, Kerasidou O, Efstathiou N, Papaharitou S, Hatzimouratidis K, Hatzichristou D: Medical students' attitudes toward patient-centred care: a longitudinal survey. Medical Education 2007, 41(2):146-153.

16. Haidet P, Dains JE, Paterniti DA, Hechtel L, Chang T, Tseng E, Rogers JC: Medical student attitudes toward the doctor-patient relationship. Medical Eduation 2002, 36(6):568-574.

17. Lévesque M, Hovey R, Bedos C: Advancing patient-centered care through transformative educational leadership: a critical review of health care professional preparation for patient-centered care. Journal of Healthcare Leadership 2013, 5:35-46.

18. Kern DE, Branch Jr WT, Jackson JL, Brady DW, Feldman MD, Levinson W, Lipkin Jr M: Teaching the psychosocial aspects of care in the clinical setting: practical recommendations. Academic Medicine 2005, 80(1):8-20.

19. Neumann M, Edelhäuser F, Tauschel D, Fischer MR, Wirtz M, Woopen C, Haramati A, Scheffer C: Empathy decline and its reasons: a systematic review of studies with medical students and residents. Academic medicine 2011, 86(8):996-1009.

20. Bombeke K, Symons L, Debaene L, De Winter B, Schol S, Van Royen P: Help, I'm losing patient-centredness! Experiences of medical students and their teachers. Medical Education 2010, 44(7):662-673.

21. Levinson W, Lesser CS, Epstein RM: Developing physician communication skills for patient-centered care. Health affairs 2010, 29(7):1310-1318.

22. Lee KH, Seow A, Luo N, Koh D: Attitudes towards the doctor-patient relationship: a prospective study in an Asian medical school. Medical Education 2008, 42(11):1092-1099.

23. Krupat E, Hiam CM, Fleming MZ, Freeman P: Patient-centeredness and its correlates among first year medical students. The International Journal of Psychiatry in Medicine 1999, 29(3):347-356.

24. Madhan B, Rajpurohit AS, Gayathri H: Attitudes of postgraduate orthodontic students in India towards patientcentered care. Journal of Dental Education 2011, 75(1):107-114. 
25. Roter DL, Hall JA, Aoki Y: Physician gender effects in medical communication: a meta-analytic review. JAMA 2002, 288(6):756-764.

26. Hurley EA, Doumbia S, Kennedy CE, Winch PJ, Roter DL, Murray SM, Harvey SA: Patient-centred attitudes among medical students in Mali, West Africa: a cross-sectional study. BMJ open 2018, 8(1):e019224.

27. Mead N, Bower P: Patient-centredness: a conceptual framework and review of the empirical literature. Social Science and Medicine 2000, 51(7):1087-1110.

28. Zill JM, Scholl I, Härter M, Dirmaier J: Which dimensions of patient-centeredness matter?-Results of a web-based expert delphi survey. PloS one 2015, 10(11).

29. Mercer SW, Reynolds WJ: Empathy and quality of care. British Journal of General Practice 2002, 52(Suppl):S9-12.

30. Del Canale S, Louis DZ, Maio V, Wang X, Rossi G, Hojat M, Gonnella JS: The relationship between physician empathy and disease complications: an empirical study of primary care physicians and their diabetic patients in Parma, Italy. Academic Medicine 2012, 87(9):1243-1249.

31. Worly B, Verbeck N, Walker C, Clinchot DM: Burnout, perceived stress, and empathic concern: differences in female and male Millennial medical students. Psychology, Health and Medicine 2019, 24(4):429-438.

32. Wimmers PF, Stuber ML: Assessing medical students' empathy and attitudes towards patient-centered care with an existing clinical performance exam (OSCE). Procedia-Social Behavioral Sciences 2010, 2(2):1911-1913.

33. Michael K, Dror MG, Karnieli-Miller OJPe, counseling: Students' patient-centered-care attitudes: The contribution of self-efficacy, communication, and empathy. Patient education and counseling 2019, 102(11):2031-2037.

34. Satterfield JM, Hughes E: Emotion skills training for medical students: a systematic review. Medical education 2007, 41(10):935-941.

35. Winefield HR, Chur-Hansen A: Evaluating the outcome of communication skill teaching for entry-level medical students: does knowledge of empathy increase? Medical Education 2000, 34(2):90-94.

36. Rees C, Sheard C, Davies S: The development of a scale to measure medical students' attitudes towards communication skills learning: the Communication Skills Attitude Scale (CSAS). Medical Education 2002, 36(2):141-147.

37. Rees C, Sheard C: The relationship between medical students' attitudes towards communication skills learning and their demographic and education-related characteristics. Medical Education 2002, 36(11):1017-1027.

38. Cleland J, Foster K, Moffat M: Undergraduate students' attitudes to communication skills learning differ depending on year of study and gender. Medical Teacher 2005, 27(3):246-251.

39. Scambler S, Delgado M, Asimakopoulou K: Defining patient-centred care in dentistry? A systematic review of the dental literature. British dental journal 2016, 221(8):477.

40. Krupat E, Yeager CM, Putnam S: Patient role orientations, doctor-patient fit, and visit satisfaction. Psychology \& Health 2000, 15(5):707-719.

41. Kang I, Kee S-W, Kim S-E, Jeong B-S, Hwang J-H, Song J-E, Kim J-W: Reliability and validity of the Korean-version of Interpersonal Reactivity Index. Journal of Korean Neuropsychiatric Association 2009, 48(5):352-358.

42. Kim K-J: Project-based learning approach to increase medical student empathy. Medical Education Online 2020, 25(1):1742965.

43. Anvik T, Gude T, Grimstad H, Baerheim A, Fasmer OB, Hjortdahl P, Holen A, Risberg T, Vaglum P: Assessing medical students' attitudes towards learning communication skills-which components of attitudes do we measure? BMC Medical Education 2007, 7(1):4.

44. Hur Y, Cho AR, Choi CJ: Medical students' and patients' perceptions of patient-centred attitude. Korean Journal of Medical Education 2017, 29(1):33.

Page $12 / 17$ 
45. Tsimtsiou Z, Kirana P-S, Hatzichristou D: Determinants of patients' attitudes toward patient-centered care: A cross-sectional study in Greece. Journal of Patient Education and Counseling 2014, 97(3):391-395.

46. Beattie A, Durham J, Harvey J, Steele J, McHanwell S: Does empathy change in first-year dental students? European Journal of Dental Education 2012, 16(1):e111-e116.

47. Ishikawa H, Son D, Eto M, Kitamura K, Kiuchi T: Changes in patient-centered attitude and confidence in communicating with patients: a longitudinal study of resident physicians. BMC Medical Education 2018, 18(1):20.

48. Ribeiro MMF, Krupat E, Amaral CFS: Brazilian medical students' attitudes towards patient-centered care. Journal of Medical Teacher 2007, 29(6):e204-e208.

49. Michael K, Dror MG, Karnieli-Miller O: Students' patient-centered-care attitudes: The contribution of self-efficacy, communication, and empathy. Patient Education and Counseling 2019, 102(11):2031-2037.

50. Hojat M, Gonnella JS, Nasca TJ, Mangione S, Vergare M, Magee M: Physician empathy: definition, components, measurement, and relationship to gender and specialty. American Journal of Psychiatry 2002, 159(9):1563-1569.

51. Davis MH: Measuring individual differences in empathy: Evidence for a multidimensional approach. Journal of Personality and Social Psychology 1983, 44(1):113.

52. Pulos S, Elison J, Lennon R: The hierarchical structure of the Interpersonal Reactivity Index. Social Behavior and Personality 2004, 32(4):355-360.

53. Hojat M, Mangione S, Kane GC, Gonnella JS: Relationships between scores of the Jefferson scale of physician empathy (JSPE) and the interpersonal reactivity index (IRI). Medical Teacher 2005, 27(7):625-628.

54. Davis MH: A multidimensional approach to individual differences in empathy. Journal of Personality and Social Psychology 1980, 44:113-126.

55. Dohrenwend AM: Defining empathy to better teach, measure, and understand its impact. Academic Medicine 2018, 93(12):1754-1756.

56. Yarnold PR, Bryant F, Nightingale S, Martin G: Assessing physician empathy using the Interpersonal Reactivity Index: A measurement model and cross-sectional analysis. Journal of Personality Social Psychology 1996, 1(2):207-221.

57. Eisenberg N, Fabes RA, Murphy B, Karbon M, Maszk P, Smith M, O'Boyle C, Suh K: The relations of emotionality and regulation to dispositional and situational empathy-related responding. Journal of Personality Social Psychology 1994, 66(4):776.

58. Nielsen HG, Tulinius C: Preventing burnout among general practitioners: is there a possible route? Education for Primary Care 2009, 20(5):353-359.

59. von Harscher H, Desmarais N, Dollinger R, Grossman S, Aldana S: The impact of empathy on burnout in medical students: new findings. Psychology, Health \& Medicine 2018, 23(3):295-303.

60. Batt-Rawden SA, Chisolm MS, Anton B, Flickinger TE: Teaching empathy to medical students: an updated, systematic review. Academic Medicine 2013, 88(8):1171-1177.

\section{Tables}

Table 1 Descriptive statistics of survey respondents $(n=312)$ 


\begin{tabular}{|lll|}
\hline Characteristics & No. & $\%$ \\
\hline Sex & 312 & \\
\hline Male & 177 & 56.7 \\
\hline Female & 135 & 43.3 \\
\hline Age groups & M $=22.39$ & SD $=3.02$ \\
\hline$\leq 25$ y & 261 & 83.7 \\
\hline$>25$ y & 51 & 16.3 \\
\hline Academic track & & \\
\hline Dental college & 193 & 61.9 \\
\hline Professional graduate-entry school & 119 & 38.1 \\
\hline Academic Period & M 2.92 & SD $=1.77$ \\
\hline$\leq 3$ y & 221 & 70.8 \\
\hline$>3$ y & 91 & 29.2 \\
\hline Future career plan & & \\
\hline Private practitioner & 158 & $50.60 \%$ \\
\hline Clinical professor & 39 & $27.90 \%$ \\
\hline Associate doctor & 28 & $12.50 \%$ \\
\hline Other/Don't know & & $9.00 \%$ \\
\hline
\end{tabular}

Table 2 Survey responses for the Patient-Practitioner Orientation Scale (PPOS), Interpersonal Reactivity Index (IRI), and Communication Skills Attitude Scale (CSAS) score 


\begin{tabular}{|lcc|}
\hline Variable & $M$ & $S D$ \\
\hline Patient-Practitioner Orientation Scale (PPOS) & & \\
\hline PPOS (Sharing) & 3.78 & 0.54 \\
\hline PPOS (Caring) & 4.41 & 0.52 \\
\hline PPOS (Total) & 4.09 & 0.45 \\
\hline Empathy (IRI) & & \\
IRI (Fantasy) & 3.52 & 0.62 \\
\hline IRI (Empathic Concern) & 3.66 & 0.52 \\
\hline IRI (Perspective Taking) & 3.69 & 0.5 \\
\hline IRI (Personal Distress) & 2.95 & 0.51 \\
\hline Communication Skills Attitude Scale (CSAS) & & \\
\hline Positive Attitudes Scale (CSAS-PAS) & 4.09 & 0.61 \\
\hline Negative attitudes scale (CSAS-NAS) & 2.59 & 0.93 \\
\hline
\end{tabular}

Table 3 Comparison of male and female dental student scores on the patient-practitioner orientation scale (PPOS), interpersonal reactivity index (IRI), and Communication Skills Attitude Scale (CSAS) 


\begin{tabular}{|c|c|c|c|c|c|c|c|c|c|c|}
\hline \multirow[t]{2}{*}{ Instrument } & \multirow[t]{2}{*}{ Item group } & \multirow[t]{2}{*}{$\mathrm{n}$} & \multirow[t]{2}{*}{$\begin{array}{l}\text { Mean } \\
\text { score }\end{array}$} & \multirow[t]{2}{*}{ SD } & \multirow[t]{2}{*}{$\begin{array}{l}\text { t- } \\
\text { value }\end{array}$} & \multirow[t]{2}{*}{$\begin{array}{l}\text { Degree } \\
\text { of } \\
\text { freedom }\end{array}$} & \multirow[t]{2}{*}{$\mathrm{p}$} & \multirow[t]{2}{*}{$\begin{array}{l}\text { Mean } \\
\text { difference }\end{array}$} & \multicolumn{2}{|c|}{$\begin{array}{l}95 \% \\
\text { Confidence } \\
\text { Interval }\end{array}$} \\
\hline & & & & & & & & & Lower & Upper \\
\hline \multirow[t]{6}{*}{ PPOS } & \multirow[t]{2}{*}{ Sharing } & $\begin{array}{l}\text { Male = } \\
177\end{array}$ & 3.72 & 0.54 & \multirow[t]{2}{*}{-2.38} & \multirow[t]{2}{*}{310} & \multirow[t]{2}{*}{0.02} & \multirow[t]{2}{*}{-0.15} & \multirow[t]{2}{*}{-0.26} & \multirow[t]{2}{*}{-0.03} \\
\hline & & $\begin{array}{l}\text { Female } \\
=135\end{array}$ & 3.86 & 0.52 & & & & & & \\
\hline & \multirow[t]{2}{*}{ Caring } & $\begin{array}{l}\text { Male = } \\
177\end{array}$ & 4.38 & 0.56 & \multirow[t]{2}{*}{-0.99} & \multirow[t]{2}{*}{310} & \multirow[t]{2}{*}{0.32} & \multirow[t]{2}{*}{-0.06} & \multirow[t]{2}{*}{-0.18} & \multirow[t]{2}{*}{0.06} \\
\hline & & $\begin{array}{l}\text { Female } \\
=135\end{array}$ & 4.44 & 0.46 & & & & & & \\
\hline & \multirow[t]{2}{*}{ Total } & $\begin{array}{l}\text { Male = } \\
177\end{array}$ & 4.05 & 0.48 & \multirow[t]{2}{*}{-1.99} & \multirow[t]{2}{*}{310} & \multirow[t]{2}{*}{0.04} & \multirow[t]{2}{*}{-0.1} & \multirow[t]{2}{*}{-0.2} & \multirow[t]{2}{*}{0} \\
\hline & & $\begin{array}{l}\text { Female } \\
=135\end{array}$ & 4.15 & 0.4 & & & & & & \\
\hline \multirow[t]{8}{*}{ IRI } & \multirow[t]{2}{*}{ Fantasy } & $\begin{array}{l}\text { Male = } \\
177\end{array}$ & 3.47 & 0.65 & -1.65 & 310 & 0.1 & -0.12 & -0.26 & 0.02 \\
\hline & & $\begin{array}{l}\text { Female } \\
=135\end{array}$ & 3.59 & 0.59 & & & & & & \\
\hline & $\begin{array}{l}\text { Empathic } \\
\text { concern }\end{array}$ & $\begin{array}{l}\text { Male = } \\
177\end{array}$ & 3.63 & 0.56 & -1.19 & 310 & 0.24 & -0.07 & -0.19 & 0.05 \\
\hline & & $\begin{array}{l}\text { Female } \\
=135\end{array}$ & 3.7 & 0.46 & & & & & & \\
\hline & $\begin{array}{l}\text { Perspective } \\
\text { taking }\end{array}$ & $\begin{array}{l}\text { Male = } \\
177\end{array}$ & 3.72 & 0.53 & 1.13 & 310 & 0.26 & 0.06 & -0.05 & 0.18 \\
\hline & & $\begin{array}{l}\text { Female } \\
=135\end{array}$ & 3.65 & 0.45 & & & & & & \\
\hline & $\begin{array}{l}\text { Personal } \\
\text { distress }\end{array}$ & $\begin{array}{l}\text { Male = } \\
177\end{array}$ & 2.88 & 0.52 & -2.85 & 310 & 0 & -0.17 & -0.28 & -0.05 \\
\hline & & $\begin{array}{l}\text { Female } \\
=135\end{array}$ & 3.05 & 0.49 & & & & & & \\
\hline CSAS & Positive & $\begin{array}{l}\text { Male = } \\
177\end{array}$ & 53.86 & 6.38 & -0.92 & 289.63 & 0.36 & -0.67 & -2.1 & 0.76 \\
\hline & & $\begin{array}{l}\text { Female } \\
=135\end{array}$ & 54.53 & 6.33 & & & & & & \\
\hline & Negative & $\begin{array}{l}\text { Male = } \\
177\end{array}$ & 32.94 & 6.12 & 1 & 296.61 & 0.31 & 0.68 & -0.65 & 2.01 \\
\hline & & $\begin{array}{l}\text { Female } \\
=135\end{array}$ & 32.26 & 5.76 & & & & & & \\
\hline
\end{tabular}

Table 4 Participant's demographic, academic characteristics, empathy, Communication Skills Attitude Scale, and PPOS scores 


\begin{tabular}{|c|c|c|c|c|c|c|c|c|c|c|}
\hline & & \multicolumn{3}{|c|}{ PPOS (Total) } & \multicolumn{3}{|c|}{ PPOS (Sharing) } & \multicolumn{3}{|c|}{ PPOS (Caring) } \\
\hline \multicolumn{2}{|c|}{ Variable } & B & Beta & $\mathrm{p}$ & B & Beta & $\mathrm{p}$ & B & Beta & $\mathrm{p}$ \\
\hline \multirow[t]{4}{*}{ Step1 } & Gender & 0.1 & 0.11 & 0.04 & 0.15 & 0.14 & 0.01 & 0.05 & 0.05 & 0.34 \\
\hline & $\begin{array}{l}\text { Academic track } \\
\text { (DC:1, } \\
\text { Professional:2) }\end{array}$ & -0.02 & -0.02 & 0.73 & -0.06 & -0.06 & 0.35 & 0.03 & 0.02 & 0.68 \\
\hline & Academic Period & -0.03 & -0.13 & 0.03 & -0.06 & -0.21 & $<0.001$ & 0 & -0.01 & 0.91 \\
\hline & Adjusted R-squared & 0.05 & & & 0.06 & & & 0.03 & & \\
\hline \multirow[t]{5}{*}{ Step2 } & IRI_Fantasy & 0.08 & 0.11 & 0.08 & 0.03 & 0.03 & 0.61 & 0.13 & 0.16 & 0.01 \\
\hline & $\begin{array}{l}\text { IRI_Empathic } \\
\text { Concern }\end{array}$ & 0.19 & 0.22 & $<0.001$ & 0.16 & 0.15 & 0.02 & 0.22 & 0.22 & $<0.001$ \\
\hline & $\begin{array}{l}\text { IRI_Perspective } \\
\text { Taking }\end{array}$ & 0.08 & 0.09 & 0.14 & 0.09 & 0.09 & 0.19 & 0.08 & 0.07 & 0.23 \\
\hline & $\begin{array}{l}\text { IRI_Personal } \\
\text { Distress }\end{array}$ & -0.07 & -0.09 & 0.14 & -0.03 & -0.03 & 0.6 & -0.12 & -0.12 & 0.04 \\
\hline & Adjusted R-squared & 0.18 & & & 0.1 & & & 0.19 & & \\
\hline \multirow[t]{3}{*}{ Step3 } & CSAS_PAS & 0.01 & 0.13 & 0.04 & 0 & 0.03 & 0.69 & 0.02 & 0.19 & $<0.001$ \\
\hline & CSAS_NAS & -0.03 & -0.34 & $<0.001$ & -0.03 & -0.31 & $<0.001$ & -0.03 & -0.28 & $<0.001$ \\
\hline & Adjusted R-squared & 0.31 & & & 0.18 & & & 0.31 & & \\
\hline
\end{tabular}

Table 5 Patient-centered attitude among different future plan

\begin{tabular}{|lllllllll|}
\hline & & \multicolumn{2}{c}{ PPOS_sharing } & \multicolumn{2}{c|}{ PPOS_caring } & \multicolumn{2}{c|}{ PPOS_total } \\
\hline & $\mathrm{n}(\%)$ & Mean & S.D. & Mean & S.D. & Mean & S.D. \\
\hline Private practitioner & $158(50.6 \%)$ & $3.66_{\mathrm{a}}$ & 0.48 & 4.31 & 0.5 & $3.98_{\mathrm{a}}$ & 0.41 \\
\hline Clinical professor & $87(27.9 \%)$ & $3.90_{\mathrm{b}}$ & 0.57 & 4.5 & 0.52 & $4.20_{\mathrm{b}}$ & 0.48 \\
\hline Associate doctor & $39(12.5 \%)$ & $3.93_{\mathrm{b}}$ & 0.55 & 4.53 & 0.49 & $4.23_{\mathrm{b}}$ & 0.4 \\
\hline Other / Don't know & $28(9.0 \%)$ & 3.9 & 0.6 & 4.49 & 0.57 & 4.19 & 0.52 \\
\hline F & 312 & $5.94^{\star \star \star}$ & $3.77^{\star *}$ & $6.68^{\star \star *}$ & \\
\hline
\end{tabular}

Notes: Significantly difference in post-hoc Tukey test at alpha $=.05: \mathrm{a}<\mathrm{b},{ }^{* \star} \mathrm{p}<<.001,{ }^{*} \mathrm{p}<0.01$ 